\title{
CDISC SDTM Epoch Terminology
}

National Cancer Institute

\section{Source}

National Cancer Institute. CDISC SDTM Epoch Terminology. NCI Thesaurus. Code C99079.

Terminology associated with the epoch codelist of the Clinical Data Interchange Standards Consortium (CDISC) Study Data Tabulation Model (SDT M). 